\title{
MINI TRAMPOLINE EXERCISES AND THE FUNCTIONAL CAPACITY OF PATIENTS WITH SPINAL PAIN
}

\author{
KAROLINA RACZYŃSKA ${ }^{1}$, GRZEGORZ ŻUREK ${ }^{2}$, RYSZARD BAREJ ${ }^{1}$, \\ OSKAR PELZER ${ }^{1}$, SIEGFRIED LEHRL ${ }^{3}$ \\ ${ }^{1}$ The KRUS “GRANIT”' Farmers' Rehabilitation Centre in Szklarska Poręba \\ ${ }^{2}$ University School of Physical Education in Wroclaw, Faculty of Physical Education, \\ Department of Anatomy \\ ${ }^{3}$ University of Erlangen, Department of Psychiatry and Psychotherapy
Mailing address: Karolina Raczyńska, The KRUS “GRANIT” Farmers' Rehabilitation Centre, 14 Kopernika Street, 58-580 Szklarska Poręba, tel.: 669585 857,
e-mail: semivit@gmail.com

\begin{abstract}
Introduction. One of the reasons for the lower quality of life of ageing patients has to do with the chronic pain they experience due to disorders of the locomotor and nervous systems. These disorders include osteoarthritis, and in particular degenerative-deforming changes in the spine, which increase the patients' tendency to fall and to suffer increasingly severe consequences as a result. Financial resources, both in Poland and in many other countries, are mainly allocated to treating patients, and it seems that measures which would help prevent falls are not being taken to a sufficient extent, bearing in mind how important fall prevention is for dealing with old age-related health issues. According to the latest medical expertise, falls can be effectively prevented if multi-disciplinary prevention programmes are implemented. These programmes consist of specially designed and varied exercises using machines and other equipment which help improve joint mobility and restore balance control. The aim to the study was to determine what impact exercises using a mini trampoline had on the functional capacity of a group of middle-aged subjects who participated in the study. Material and methods. The study was conducted at the KRUS "GRANIT” Farmers' Rehabilitation Centre in Szklarska Poręba on a group of 80 persons aged $45-55$ years (67\% of them were women and 33\% were men), who completed a mini trampoline exercise programme as part of a 21-day rehabilitation course. Before the subjects started the programme and after they completed it, basic somatic measurements were taken, tests were conducted in order to diagnose the subjects' functional capacity and the subjective level of pain experienced by the subjects was measured using a pain rating scale (VAS). Results. It was found that the regular mini trampoline exercises had had an impact on the functional capacity of the subjects and the training had significantly reduced pain in the lumbar region of the spine.
\end{abstract}

Key words: adults, functional capacity, mini trampoline

\section{Introduction}

In the past few years in Europe we have been witnessing demographic changes which have been termed among others as "the old-age time bomb" (Commission of the European Communities, Brussels 2005. The current demographic structure of an average West-European society is the result of a combination of several overlapping social and economic factors [1]. Although it is difficult to predict the effects of these changes, it is certain that this demographic shift will have an impact on more and more aspects of our lives. That is why the scope, progress and direction of these changes is being carefully observed in the European population, as well as in the American one and some of the populations in the Far East. The main focus is on the citizens of these countries and on making it possible for them to maintain good health in the face of growing life expectancy [2]. Early recognition of health problems in the elderly makes it possible to implement programmes which can prevent or reduce the effects ageing has on the human body and can have an influence on the actions undertaken by public institutions in response to the increasing number of elderly people, which by the the year 2030 will be $23.8 \%$ higher than in the previous century.
It is also important to make those who are ageing aware of the limitations they may experience in the next stages of their lives and of the methods of minimising these limitations [1]. People should be given an opportunity to start getting prepared to age in a way which will let them preserve their health, independence and well-being already when they are adolescents, and not only once they have become adults, as only learning how to maintain a healthy lifestyle at an early age can make it possible for them to develop longlasting healthy habits. However, preventive measures targeted at adults, including those currently being implemented, can also have an impact on their future in terms of giving them a chance to "age well", because people in this age group can still change their habits and become more proactive in taking care of their health.

In order to help citizens maintain their health in good condition for as long as possible, a range of programmes promoting physical activity have been implemented in several EU countries [3]. In the last few years similar measures have been introduced in Poland: more financial resources have been allocated to building new public sports facilities and to promoting an active lifestyle and generating interest in different forms of physical activity, among others thanks to several editions of the Na- 
tional Health Programme [4]. The programmes aimed at promoting physical activity and showing its practical benefits were to serve as an incentive for their beneficiaries to take care of their health by including physical activity in their daily routine. This change in lifestyle is to delay the effects of ageing and allow the beneficiaries to maintain their autonomy and independence at old age, making them less dependent on others [5].

One major problem that can restrict the personal and functional independence of elderly people is the probability of falling. If a fall occurs, it may significantly affect their quality of life. A fall can often cause an older person to be confined to their home due to their restricted mobility; the immobilisation can launch a series of complications, which can ultimately be lifethreatening [6]. The results of studies conducted so far have shown that there are approximately 400 risk factors associated with falls, which are either external, that is having to with the conditions of a person's life, or internal, that is related to their health condition [7]. The risk factors connected with an elderly person's health condition, physical fitness and their place of residence which are mentioned the most frequently include: balance and walking disorders, the fear of falling, visual impairment, a high risk for osteoporosis, mood disorders, dizziness, mobility impairment, reduced muscle strength and problems with motor coordination [8, 9]. The first signs of muscle weakening are recorded between the ages of 30 and 40, which is why it would be advantageous to promote physical activity among the working-age population. It is estimated that approximately $36 \%$ of persons aged 65 or more fall once in a year [10].

The research conducted so far shows, among others, that maintaining good health reduces the risk of falling in persons aged over 50 years. This can be achieved through physical exercise aimed at improving balance, coordination and muscle strength [11]. Such exercises should ideally impact the following four areas: strength and balance, eye sight, the cardiovascular system and cognitive function; in addition, the medication taken by the patient should be verified [7]. Among the four areas mentioned above strength and balance training is the most efficient method in terms of its effects on a person's quality of life. The prevention programmes for elderly people which are currently being implemented tend to include exercises which are to improve joint mobility, increase muscle strength and mass, as well as eliminate improper body posture [7, 12].

Those who design programmes whose goal is to prevent falls and minimise their consequences try to find low-cost and universal solutions, whose implementation would make it possible to impact as large a group of people as possible. The type of exercise that has recently been promoted in Europe and in the USA is training using unstable surfaces. Comprehensive fall prevention training should include exercises which improve balance, strengthen postural muscles and change the posture of the body [13]. Such exercises may be done using a mini trampoline. Exercising on this an unstable surface has the same effect as exercise using such equipment as balancing boards and stepping stones, or that done in therapeutic gardens, in that it helps improve one's coordination and stimulates proprioception [14, 15]. When performing such exercises using a trampoline, a person usually does not jump, but only sways, balancing their body and causing different muscles to tense and relax, which is beneficial for the musculoskeletal system, including the ligaments $[16,17]$. During such movement many auxotonic contractions are generated in the body, that is contractions which have to with an increase in muscle tension and a change in muscle length. These are the most natural muscle contractions, which occur during almost any type of dynamic activity, such as walking or jumping, that strengthen the muscles [18]. Another positive aspect of mini trampoline training is practising controlling body posture, which needs to be proper if the exercises are to be done correctly. Moreover, this type of training includes balance, coordination and elongation exercises. All these elements of mini trampoline training activate the sensorimotor system and, as a result, improve functional capacity [15, 16, 17].

The trampoline has been known and used for many years both in Poland and around the world, but it has mainly been used as a device for children to play with kept in the garden, rather than a piece of equipment for performing controlled and specially designed physical exercises. Meanwhile, mini trampoline training could become a commonly available alternative method of improving muscle strength and restoring motor coordination, and, most of all, an innovative preventive measure for minimising the consequences of ageing and for avoiding falls [19, 20]. For these reasons one should consider incorporating mini trampolines in programmes promoting the physical activity of children, adults and the elderly.

Since there is a limited body of research concerning the impact of mini trampoline training on the functional capacity of people of different ages, the aim of this study was to explore the effectiveness of this type of training in adults. The exercise programme described in this study was implemented at a sanatorium, where there were many patients who suffered from pain in the lumbar region of the spine, thus an additional goal of the study was to assess to what extent mini trampoline training would be effective in reducing this type of pain.

To sum up, the study was to assess the effectiveness of mini trampoline exercises performed during a rehabilitation course of standard length on the level of functional capacity of the adult subjects and determine to what extent these exercises had impacted the level of pain experienced by them.

The research questions were the following:

1. Will regular mini trampoline training have an effect on the functional capacity of the group of adults?

2. Will the adult subjects, who will be performing regular mini trampoline exercises, notice a change in the level of spinal pain they experience?

\section{Material and methods}

The mini trampoline exercise programme, which was intended as a pilot version, was implemented during rehabilitation courses between February and April 2014. A total of 80 persons participated in the programme. They group consisted of 54 women (67\%) and 26 men (33\%) aged 45-55 years (their mean age was 50.98 years), who were undergoing therapy at the KRUS "GRANIT" Farmers' Rehabilitation Centre in Szklarska Poręba. The persons selected for the study had been diagnosed with degenerative disease of the lumbosacral spine, first degree spondyloarthritis, and, according to the doctors, their symptoms and clinical state were similar. The persons were qualified for the study following the recommendations of the doctors and when exercising they were supervised by a physiotherapist, who was a qualified mini trampoline training instructor.

The exercise sessions took place every day from Monday to Saturday around noon (11 a.m. until 1 p.m) in small groups of no more than 14 persons. This was the only form of physical activity for the group studied during their stay at the sanatorium.

For safety reasons the following type of mini trampoline was used: a mini trampoline with a jumping surface of 1 metre in diameter, a height of 28 centimetres and 8 legs. Safety mats and railings adjusted to the needs of the subjects were additionally used. The trampolines used in the study had a CE/TUV/GS safety certificate.

The data used to assess the subjects were recorded using an assessment sheet which included information concerning the age and gender of the subjects. Moreover, basic somatic features were measured twice. These included the subjects' height and body mass (based on which the BMI was calculated), heart rate, 
blood pressure, and the waist and hip circumferences.

In order to assess the subjects' functional capacity, the following were measured twice:

- Flexibility (using the sitting and reaching test). The subjects sat on a chair with one leg straight and they bent forward trying to reach the toes of their left foot. The result was measured using measuring tape. The test was done three times and the best result was recorded.

- Endurance (using a 2-minute test consisting in marching in place and lifting one's knees high). The number of cycles of the exercise completed by the subjects was recorded.

- Lower extremity muscle strength (using a sitting and rising test). The number of instances when a subject rose from sitting on the chair to a standing position in 30 seconds, with the arms were crossed across the chest, was recorded.

In addition, the level of pain experienced by the subjects was measured using the VAS scale. The subjects were asked to rate the level of pain they were experiencing in the lumbosacral spine region by choosing number from 0 to 10, indicating no pain and the strongest pain imaginable, respectively, using a specially prepared pain rating scale.

All of the measurements were performed in the morning at the beginning and end of the rehabilitation course which lasted 21 days. The exercises were done over 17 days, since the day of arrival and departure and the days of examinations performed at the beginning and end of the course were excluded from the training programme.

The mini trampoline exercises were done in three stages. Each session began with the participants saying how they were feeling and with the instructor discussing some safety rules that should be followed when exercising.

During the first week (the 1st stage lasting 25 minutes) simple exercises combining pulsating movements with different types of arm movement were done. The exercises were accompanied by slow music (75 BPM). The session started with a warm-up, which was followed by the main exercises, and it finished with stretching and breathing exercises.

In the second week (the 2nd stage lasting 30 minutes) the sessions again consisted of a warm-up, the main exercises and a breathing and stretching session. At this stage exercises combining pulsating movements and marching with different types of arm movement were done. An increased number of coordination exercises were introduced; these exercises needed to have at least one of the following four features: they needed to be new, uncommon, complex or difficult. The exercises were done at a moderate pace (100 BPM).

During the third week (the 3rd stage lasting 35 minutes) the subjects did exercises accompanied by fast-paced music (120 $\mathrm{BPM}$ ). The subjects performed exercises combining pulsating movements and marching with different types of arm movement, which were made more difficult due to the increased complexity of the movements in a given exercise. The main exercises were done for 30 minutes.

The results of the initial and final measurements were analysed using the statistical package PQStat version 1.4.2.324. Basic statistical values were calculated and the sets of data were compared using Student's t-test. Statistical significance was set at $\mathrm{p}<0.05$.

\section{Results}

The mean age of the women who participated in the study was slightly above 50 years, whereas that of the male participants was 52 years. In neither the female nor the male participants of the study were significant changes recorded in body mass, BMI, or the waist and hip circumferences. However, significant changes were found with regard to the tests measuring functional capacity which were used, namely the sitting and reaching test, sitting and rising test, 2-minute marching in place test and the pain level assessment carried out by means of the VAS scale.

Table 1. Statistical data concerning the results of the assessment of somatic features, functional tests, and pain assessment for the female participants of the study

\begin{tabular}{|c|c|c|c|c|}
\hline & $\begin{array}{l}\text { Descriptive } \\
\text { statistics }\end{array}$ & $\begin{array}{c}\text { Initial } \\
\text { measurement }\end{array}$ & $\begin{array}{c}\text { Final } \\
\text { measurement }\end{array}$ & $\begin{array}{c}\text { Student's } \\
\text { t-test }\end{array}$ \\
\hline \multirow{3}{*}{ Height } & $x$ & 1.63 & & \\
\hline & SD & 0.045 & & \\
\hline & $\mathrm{v}$ & 36.53 & & \\
\hline \multirow{3}{*}{ Body mass } & $\mathrm{x}$ & 71.32 & 70.62 & \multirow{3}{*}{$\begin{array}{l}t=4.13 \\
p>0.05\end{array}$} \\
\hline & SD & 12.82 & 13.34 & \\
\hline & v & 5.56 & 5.72 & \\
\hline \multirow{3}{*}{ Hip circumference } & $x$ & 99.50 & 97.78 & \multirow{3}{*}{$\begin{array}{l}t=3.09 \\
p>0.05\end{array}$} \\
\hline & SD & 12.42 & 12.41 & \\
\hline & $\mathrm{v}$ & 8.01 & 7.88 & \\
\hline \multirow{3}{*}{ Waist circumference } & $x$ & 88.67 & 86.78 & \multirow{3}{*}{$\begin{array}{l}t=3.21 \\
p>0.05\end{array}$} \\
\hline & SD & 15.10 & 14.38 & \\
\hline & $\mathrm{v}$ & 5.87 & 6.04 & \\
\hline \multirow{3}{*}{ BMI } & $x$ & 26.63 & 36.37 & \multirow{3}{*}{$\begin{array}{l}t=4.13 \\
p>0.05\end{array}$} \\
\hline & SD & 4.42 & 4.27 & \\
\hline & $\mathrm{v}$ & 6.03 & 6.18 & \\
\hline \multirow{3}{*}{ VAS pain scale } & $x$ & 5.52 & 3.81 & \multirow{3}{*}{$\begin{array}{c}t=8.02 \\
p<0.05\end{array}$} \\
\hline & SD & 1.98 & 1.90 & \\
\hline & $\mathrm{v}$ & 2.79 & 2.00 & \\
\hline \multirow{3}{*}{$\begin{array}{l}\text { Sitting and rising test } \\
\text { (number of repetitions) }\end{array}$} & $\mathrm{x}$ & 16.76 & 18.07 & \multirow{3}{*}{$\begin{array}{c}t=6.71 \\
p<0.05\end{array}$} \\
\hline & SD & 2.87 & 2.91 & \\
\hline & $\mathrm{v}$ & 5.83 & 6.22 & \\
\hline \multirow{3}{*}{$\begin{array}{l}\text { 2-minute marching } \\
\text { in place test }\end{array}$} & $x$ & 90.07 & 93.00 & \multirow{3}{*}{$\begin{array}{c}t=5.13 \\
p<0.05\end{array}$} \\
\hline & SD & 13.53 & 14.06 & \\
\hline & $\mathrm{v}$ & 6.66 & 6.61 & \\
\hline \multirow{3}{*}{$\begin{array}{l}\text { Sitting } \\
\text { and reaching test }\end{array}$} & $\mathrm{x}$ & 0.29 & 0.73 & \multirow{3}{*}{$\begin{array}{c}t=1.59 \\
p<0.05\end{array}$} \\
\hline & SD & 2.17 & 2.10 & \\
\hline & $\mathrm{v}$ & 0.36 & 0.35 & \\
\hline
\end{tabular}

$\mathrm{x}$ - mean;

SD - standard deviation;

$\mathrm{v}$ - coefficient of variation. 
Table 2. Statistical data concerning the results of the assessment of somatic features, functional tests, and pain assessment for the male participants of the study

\begin{tabular}{|c|c|c|c|c|}
\hline & $\begin{array}{l}\text { Descriptive } \\
\text { statistics }\end{array}$ & $\begin{array}{c}\text { Initial } \\
\text { measurement }\end{array}$ & $\begin{array}{c}\text { Final } \\
\text { measurement }\end{array}$ & $\begin{array}{c}\text { Student's } \\
\text { t-test }\end{array}$ \\
\hline \multirow{3}{*}{ Height } & $x$ & 1.74 & & \\
\hline & SD & 0.08 & & \\
\hline & $\mathrm{v}$ & 21.83 & & \\
\hline \multirow{3}{*}{ Body mass } & $x$ & 83.81 & 82.60 & \multirow{3}{*}{$\begin{array}{l}t=4.15 \\
p>0.05\end{array}$} \\
\hline & SD & 15.16 & 14.87 & \\
\hline & $\mathrm{v}$ & 5.53 & 5.55 & \\
\hline \multirow{3}{*}{ Hip circumference } & $x$ & 101.85 & 101.35 & \multirow{3}{*}{$\begin{array}{l}t=1.21 \\
p>0.05\end{array}$} \\
\hline & SD & 7.32 & 6.73 & \\
\hline & $\mathrm{v}$ & 13.91 & 15.05 & \\
\hline \multirow{3}{*}{ Waist circumference } & $x$ & 95.98 & 95.02 & \multirow{3}{*}{$\begin{array}{l}t=2.19 \\
p>0.05\end{array}$} \\
\hline & SD & 10.37 & 10.23 & \\
\hline & $\mathrm{v}$ & 9.26 & 9.29 & \\
\hline \multirow{3}{*}{ BMI } & $\mathrm{x}$ & 27.31 & 26.92 & \multirow{3}{*}{$\begin{array}{l}t=4.19 \\
p>0.05\end{array}$} \\
\hline & SD & 3.91 & 3.81 & \\
\hline & $\mathrm{v}$ & 6.98 & 7.06 & \\
\hline \multirow{3}{*}{ VAS pain scale } & $x$ & 5.69 & 3.96 & \multirow{3}{*}{$\begin{array}{c}t=5.64 \\
p<0.05\end{array}$} \\
\hline & SD & 1.69 & 1.73 & \\
\hline & $\mathrm{v}$ & 3.37 & 2.29 & \\
\hline \multirow{3}{*}{$\begin{array}{l}\text { Sitting and rising test } \\
\text { (number of repetitions) }\end{array}$} & $x$ & 17.23 & 18.35 & \multirow{3}{*}{$\begin{array}{l}t=5.10 \\
p<0.05\end{array}$} \\
\hline & SD & 2.96 & 2.98 & \\
\hline & $\mathrm{v}$ & 5.83 & 6.16 & \\
\hline \multirow{3}{*}{$\begin{array}{l}\text { 2-minute marching } \\
\text { in place test }\end{array}$} & $x$ & 90.54 & 93.88 & \multirow{3}{*}{$\begin{array}{l}t=2.76 \\
p<0.05\end{array}$} \\
\hline & SD & 13.31 & 15.04 & \\
\hline & $\mathrm{v}$ & 6.80 & 6.24 & \\
\hline \multirow{3}{*}{$\begin{array}{l}\text { Sitting } \\
\text { and reaching test }\end{array}$} & $x$ & 0.20 & 0.12 & \multirow{3}{*}{$\begin{array}{l}t=1.84 \\
p<0.05\end{array}$} \\
\hline & SD & 1.92 & 1.88 & \\
\hline & $\mathrm{v}$ & 0.11 & 0.07 & \\
\hline
\end{tabular}

$\mathrm{x}$ - mean;

$\mathrm{SD}$ - standard deviation;

$\mathrm{v}-$ coefficient of variation.

A positive change was also recorded for flexibility in some of the participants. The initial measurements taken for the women and the men indicated low flexibility of the spine; after the subjects had completed the exercise programme, the results for the women had improved by 0.5 centimetre on average, but no change was found in the male participants.

In the sitting and rising test the mean number of repetitions for the female participants increased from nearly 17 to over 18, and in the male ones from more than 17 to 18.35 repetitions. Thus, according to the results of the measurements, the lower extremity muscles had become stronger in both the female and male participants. The differences between the initial and final measurements were statistically significant.

Some improvement was also recorded in the 2-minute marching in place test: the women were able to do 93 cycles in the final measurement compared to nearly 90 in the initial one, and the men completed nearly 94 cycles compared to 90.54 . The results of the test would indicate that the subjects' endurance had increased.

The results of the pain assessment using the VAS scale also changed between the initial and final measurement: the subjects' scores fell from a mean value of 5.52 to 3.81 points for the women, and 5.69 to 3.96 for the men, which would mean that the pain initially perceived as moderate by subjects of both genders was seen as mild at the end of the rehabilitation course. It is worth emphasising that the results of the pain assessment were statistically significant.

The results of the assessment which was conducted show that the subjects' functional capacity increased as a result of doing exercises using mini trampolines, which is a good argument in favour of continuing to research this area.

\section{Discussion}

For a long time mini trampoline exercises were treated as an activity which is suitable mainly for children and adolescents. Despite the fact that the producers of mini trampolines market exercising using their products as beneficial for the cardiovascular and respiratory systems, and for muscle strength, in past 30 years few comprehensive studies have been conducted which would confirm these benefits. The results of studies that are available mainly concern the impact of such training on motor coordination and maintaining balance, as well as injuries that may be sustained when jumping on a trampoline [19]. A certain change in the way trampoline training is being approached is evidenced among others by the studies conducted jointly by scientists from the University of Kentucky and from NASA, which show that during such exercises the muscles alternately tense and relax, and the biomechanical stimulation of the muscles is $68 \%$ greater than during jogging [21]. Taking into consideration the fact that mini trampoline exercises are done on an unstable surface and the variety of exercises that can be performed, ranging from balancing to jumping, it seems that mini trampoline training can be used as a major element of fall prevention programmes. What makes these findings important is that falls are considered one of "the most significant old agerelated problems". Patients aged over 50 years are already being treated in the Polish health care system due to falls, whose consequences have had a negative impact of their quality of life [5]. Most falls are due to weakening of the muscles, a decline in coordination and mobility problems. The risk of falling is an unavoidable consequence of the ageing process and can result in the patients sustaining injuries which lead to hospitalisation, mobility impairment or the irreversible loss of certain functions. Research shows that due to the fast pace at which the Polish society is ageing and to the increasing percentage of persons aged more than 50 years, the number of people who are at risk for falls and the resulting complications is growing steadily [22].

Lowering the risk of falling in the elderly is a difficult task, but it is feasible. The best results can be achieved using multidisciplinary measures which target most of the risk factors in a given person. Prevention programmes should be introduced long before the first risk factors for falling develop, that is either before or immediately after a person turns 50 years. The prevention programmes that should be implemented should include eliminating any potential risk factors for falling, educating patients and improving their functional capacity [23, 24].

Several studies have proved that one of the most effective methods of reducing the risk of falling in elderly patients is resistance training. It delays the decline in body mass and muscle strength even in people over 50 years of age and additionally helps maintain balance and coordination. That is why properly selected resistance exercises are often used as part of therapy and rehabilitation. Such exercises should be done under the supervision of qualified physiotherapists, because they require extensive knowledge concerning the patients' capacities and risks related to their health condition. The findings of some studies show that mini trampoline training has helped improve lower extremity muscle strength, balance and prioperception $[19,20]$. The results of the current study are similar to the findings of those mentioned above, as in this study an increase in the strength and endurance of the lower extremity muscles have also been observed. Another important finding of this study is the fact that the pain in the lumbosacral region of the spine had decreased, which was not only beneficial in terms of im- 
proving the subjects' quality of life, but also helped lower the risk of falling in the subjects.

The exercises which were implemented were aimed at improving the subjects' physical fitness, coordination and prioperception. The results of the study confirmed that the regular properly selected mini trampoline exercises helped improve the subjects' functional capacity. Implementing prevention programmes in Poland which would include physical exercise and patient education would reduce the risk of falling in the elderly and make it possible for the citizens to do their work in an effective and efficient way.

\section{Conclusions}

The following conclusions may be drawn based on the study and its findings:

1. Regular trampoline exercises improved the functional capacity of the subjects in terms of their flexibility, endurance and lower extremity muscle strength.

2. The subjects declared that the pain in the lumbosacral region of the spine had decreased.

3. The findings for the group of participants in this study suggest that exercising using a mini trampoline can have a significant impact on joint mobility, balance and functional capacity. The results of this study thus justify conducting further research in this field.

\section{Literature}

1. Osiński W. (2013). Gerokinesiology - the science and practice of physical activity for the elderly. Warszawa: PZWL. [in Polish]

2. Szpringer M., Wybraniec-Lewicka B., Czerwiak B., Michalska M., Krawczyńska J. (2008). Falls and injuries in geriatic age. Studia Medyczne 9, 77-81. [in Polish]

3. Kryńska E., Szukalski P. (2013). Active ageing measures in European Union countries. Final report. Łódź: Universytet Łódzki. [in Polish]

4. Department of Health and Social Services (2007) National Health Programme for the years 2007-2015. Warszawa: Ministerstwo Zdrowia i Opieki Społecznej. [in Polish]

5. Bień B., Synak B. (2011). The health condition and physical ability of elderly people in Poland in 2000. Warszawa: AWF Warszawa. [in Polish]

6. Tinetti M.E., Speechley M., Ginter S.F. (1987). Risk factors for falls among elderly persons living in the community. The New England Journal of Medicine 319, 1701-1707.

7. Czerwiński E., Borowy P., Jasiak B. (2006). Current guidelines for using physiotherapy to prevent falls. Ortopedia Traumatologia Rehabilitacja 4(6), 380-387. [in Polish]

8. Świątek J., Urodow W. (2013). Prevention of falls of the elderly people. Pielegniarstwo i Zdrowie Publiczne 3, 195-200. [in Polish]
9. Szczerbińska K. (2011). The circumstances and risk factors of recurrent and single falls in nursing homes. Gerontologia Polska 19(3-4), 161-170. [in Polish]

10. Runge M., Schacht E. (2005). Multifactorial pathogenesis of Falls as a basis for multifactorial interventions. Journal of Musculoskelet Neuronal Interact 5(2), 127-134.

11. Borzym A. (2009). Falls in old age - reasons, consequences, prophylaxis. Psychogeriatria Polska 6(2), 81-88. [in Polish]

12. Osiński W. (2002). Physical activity undertaken by elderly people. Antropomotoryka 24, 3-23. [in Polish]

13. Skalska A., Gałaś A. (2011). History of falls as a risk factor for functional decline in the elderly. Gerontologia Polska 19(3-4), 150-160. [in Polish]

14. Heitkam H., Horstman T., Maye F., Weller J., Dickhuth H. (2001). Gain in strength and muscular balance after balance training. Sports Medicine 22, 285-290.

15. Miklitsch C., Krewer C., Freivogel S., Steube D. (2013). Effects of a predefined mini-trampoline training programme on balance, mobility and activities of daily living after stroke: a randomized controlled pilot study. Clinical Rehabilitation 27(10), 39-47.

16. Hof A.L., Gazendam M.G.J., Sinke W.E. (2006). The condition for dynamic stability. Biomechanics 38(1), 1-8.

17. Kidgell D.J., Horvath D.M., Jackson B.M. (2007). Effect of six weeks of dura disc and mini-trampoline balance training on postural sway in athletes with functional ankle instability. The Journal of Strength and Conditioning Research 21(2), 466-469.

18 Bober T., Zawadzki J. (2003). Biomechanics of human movement apparatus. Wrocław: AWF Wrocław. [in Polish]

19. Aragão F.A., Karamanidis K., Vaz M.A., Arampatzis A. (2011). Mini-trampoline exercise related to mechanisms of dynamic stability improves the ability to regain balance in elderly. Journal of Electromyography and Kinesiology 21(3), 8-12.

20. Mętel S., Milert A., Szczygieł A., Drozd A., Kwiatkowska A., Krzemińska M. (2010). The influence of 6-months sensomotoric training on physical performance in the elderly with chronic back pain. Postępy Rehabilitacji 3, 51-65. [in Polish]

21. Bhattachary A., McCutcheon E., Shvartz E. (1980). Body acceleration distribution and $\mathrm{O}^{2}$ uptake in humans during running and jumping Greenleaf. Journal of Applied Physiology 49, 881-887.

22. Grodzick T., Kocemb J., Skalska A. (2006). Geriatrics with elements of gerontology: A handbook for doctors and students. Kraków: Via Medica. [in Polish]

23. Osiński W. (2011). Physical activity - can it change the brain. Wychowanie Fizyczne i Zdrowie 4, 4-9. [in Polish]

24. Edbom-Kolarz A., Marcinkowski J.T. (2011). Falls of elderly people - causes, consequences, prevention. Hygeia Public Health 46(3), 313-318. [in Polish]

Submitted: September 25, 2014

Accepted: February 5, 2014 